\title{
Dopamine-induced calcium signaling in olfactory bulb astrocytes
}

\author{
Timo Fischer*, Paula Scheffler \& Christian Lohr ${ }^{*}$ \\ It is well established that astrocytes respond to the major neurotransmitters glutamate and GABA \\ with cytosolic calcium rises, whereas less is known about the effect of dopamine on astroglial cells. \\ In the present study, we used confocal calcium imaging in mouse brain slices of the olfactory bulb, a \\ brain region with a large population of dopaminergic neurons, to investigate calcium signaling evoked \\ by dopamine in astrocytes. Our results show that application of dopamine leads to a dose-dependent \\ cytosolic calcium rise in astrocytes $\left(E C_{50}=76 \mu \mathrm{M}\right)$ which is independent of neuronal activity and \\ mainly mediated by PLC/IP $P_{3}$-dependent internal calcium release. Antagonists of both $D_{1}$ - and $D_{2}$-class \\ dopamine receptors partly reduce the dopaminergic calcium response, indicating that both receptor \\ classes contribute to dopamine-induced calcium transients in olfactory bulb astrocytes.
}

Dopamine (DA) is one of the most important modulatory neurotransmitters in the mammalian brain. It has several physiological functions in the central nervous system (CNS) including modulation of voluntary movement, reward, sleep regulation, feeding, affect, attention, cognitive function and olfaction ${ }^{1}$. Besides that, dopamine is involved in diverse diseases, such as schizophrenia, Parkinson's disease and depression. To accomplish all these functions, there are 11 populations of dopaminergic neurons distributed in the $\mathrm{CNS}^{2}$. Dopaminergic neurons in the olfactory bulb $(\mathrm{OB})$ are the most numerous among these cell groups ${ }^{3}$ and are subdivided in two subgroups: the short axon (SA) cells and a subpopulation of external tufted (ET) cells ${ }^{4}$. Within the OB, dopaminergic neurons have been reported to be found mainly in the glomerular layer, which is populated by a variety of different periglomerular interneurons. $10-16 \%$ of them are supposed to be dopaminergic ${ }^{5,6}$. A common property of the $\mathrm{OB}$ dopaminergic neurons is the ability to co-release dopamine and GABA from separate vesicle pools ${ }^{7-9}$. Dopaminergic neurons are the only catecholaminergic neurons located in the OB, hence they could be recognized by the expression of tyrosine hydroxylase $(\mathrm{TH})$, a rate-limiting enzyme in the biosynthesis of dopamine $\mathrm{s}^{10,11}$. Dopamine acts on dopamine receptors that are metabotropic $\mathrm{G}$ protein-coupled receptors containing seven transmembrane domains. Based on coupling to either $\mathrm{G \alpha}_{\mathrm{s} \text { olf }}$ proteins or $\mathrm{G \alpha}_{\mathrm{i} / \mathrm{o}}$ proteins to stimulate or inhibit the production of the second messenger cAMP, respectively, dopamine receptors are classified as $\mathrm{D}_{1}$-class receptors (including $\mathrm{D}_{1} \mathrm{R}$ and $\mathrm{D}_{5} \mathrm{R}$ ) or $\mathrm{D}_{2}$-class receptors (including $\mathrm{D}_{2} \mathrm{R}, \mathrm{D}_{3} \mathrm{R}$ and $\left.\mathrm{D}_{4} \mathrm{R}\right)^{12-14}$.

Although the actions of dopamine on neurons are well described, its influence on astroglia remains poorly understood. There has been evidence for the presence of dopamine receptors leading to cAMP production and subsequent PKA activation as well as NADH modulation and calcium signaling mediated by $\mathrm{D}_{1}$-class receptors in cultured astrocytes of different brain regions ${ }^{15-17}$. In addition to the studies above describing dopamine-induced calcium transients in cultured astrocytes, Jennings et al. (2017) and Xin et al. (2019) could demonstrate that hippocampal and midbrain astrocytes in acute brain slices respond to dopamine with a cytosolic calcium rise. However, the effect of dopamine on astrocytes in other brain regions such as the olfactory bulb remains unknown and has been investigated in the present study.

We intended to elucidate whether olfactory bulb astrocytes respond to dopamine with calcium signaling and to identify the receptor subtypes involved as well as the origin of the intracellular calcium. Our results show that astrocytes respond to bath application of dopamine with calcium release from internal stores by activation of both $\mathrm{D}_{1}$-class and $\mathrm{D}_{2}$-class receptors. 


\section{Results}

Distribution of olfactory bulb astrocytes and tyrosine hydroxylase-expressing neurons. To analyze the distribution of OB astrocytes and TH-expressing neurons in the GL and EPL by immunohistochemistry, we used TH-Cre $\times$ tdTomato $^{\mathrm{t} / / \mathrm{l}}$ mice and aimed to visualize astrocytes by anti-GFAP staining. GFAP-positive astrocytes were located throughout the GL, which can be distinguished from the ONL by glomerular structures, and the EPL, in which GFAP-expression was weaker compared to the GL (Fig. 1A). TH expression also exhibits its highest density in the GL, but the EPL also contains some TH-positive neurons and neuronal processes (Fig. 1A). In the glomerular layer, dendrites of tdTomato-positive SA cells are closely intermingled with astrocyte processes, suggesting a possible physiological interaction such as neurotransmitter release by SA cells and subsequently activation of astrocytic dopamine receptors (Fig. 1B,C). Close proximity of dendrites of TH-positive neurons and astrocyte processes could also be observed in the EPL, albeit at a lower density (Fig. 1D). In both layers, astrocyte processes were in direct vicinity of tdTomato-positive varicosities, presumptive dopamine release sites ${ }^{18}$.

Dopamine induces dose-dependent calcium transients in olfactory bulb astrocytes. A general issue in studies about astrocytes using chemical calcium indicators is the identification of astrocytes. Sulforhodamine 101 has been used to identify astrocytes in brain regions such as hippocampus and cortex but fails to label astrocytes in the brain stem ${ }^{19,20}$. We found that astrocytes in the $\mathrm{OB}$ also fail to accumulate sulforhodamine 101, however, a well-established approach for OB astrocyte identification is based on their response to ATP, ADP and low concentrations of potassium ${ }^{21,22}$. Removal of external potassium induces calcium influx into astrocytes, but not into neurons (Fig. $2 \mathrm{~A}, \mathrm{~B}$ ). Hence, the cells that did not respond to $\mathrm{K}^{+}$-free saline were presumed to be neurons. These cells also responded to $50 \mathrm{mM} \mathrm{K}^{+}$with a large calcium transient, while $100 \mu \mathrm{M}$ ADP had no effect on the calcium concentration. Astrocytes, in contrast, not only responded to $\mathrm{K}^{+}$-free saline with a calcium increase, but also to application of ADP due to expression of $\mathrm{P}_{2} \mathrm{Y}_{1}$ receptors $^{21}$ (Fig. 2A,B). According to the results mentioned above, we subsequently used the application of ADP for the identification of astrocytes and to test their viability.

In the present study, we aimed to establish whether olfactory bulb astrocytes in situ respond to dopamine application. Results were collected in the glomerular layer and the external plexiform layer that comprise most of the synapses involved in odor information processing in the olfactory bulb ${ }^{23}$. Experiments were performed in the presence of TTX to suppress action potential firing and, hence, neuronal effects on astrocytic calcium. Both short pressure application $(500 \mu \mathrm{M}$ dopamine, $2 \mathrm{~s})$ and bath application $(100 \mu \mathrm{M}$ dopamine, $30 \mathrm{~s})$ led to transient elevation in cytosolic calcium in OB astrocytes (Fig. 2C). Pressure application is a more local stimulation and enables shorter application, followed by short elevations in cytosolic calcium. However, this procedure has considerable disadvantages with regard to the comparability of the experiments. It is not possible to adjust a constant concentration, as the dopamine-containing solution applied to the cells mixes with the bath solution with increasing distance. For this reason we decided to perform all subsequent experiments using bath application. All cells that responded to dopamine with calcium transients did also respond to ADP, which was used to identify astrocytes (see above). Hence, all cells responding to dopamine were identified as astrocytes, while Fluo-8-loaded neurons did not respond to bath application of dopamine with calcium signals (Fig. 2A,B).

As shown in Fig. 2D, bath application of $100 \mu \mathrm{M}$ dopamine led to transient monophasic or oscillating elevations in cytosolic calcium in both layers. Dopamine application for 30 seconds evoked a calcium response with an amplitude of $163.9+/-3.5 \% \Delta \mathrm{F}$ and an area of $2000.6+/-69.1 \Delta \mathrm{F} * \mathrm{~s}(\mathrm{n}=328)$ in the external plexiform layer and $169.1+/-5.8 \% \Delta \mathrm{F}$ and an area of 1957.4+/-137.7 $\Delta \mathrm{F}^{*} \mathrm{~s}(\mathrm{n}=130)$ in the glomerular layer (Fig. 2E). No significant differences in amplitude and area of the responses were observed between the glomerular layer and the external plexiform layer. Hence, in all following experiments, data of both layers were pooled. Application of $100 \mu \mathrm{M}$ dopamine for several minutes evoked long-lasting calcium oscillations (Fig. 2F). For the following experiments, we opted for a relatively short application of $30 \mathrm{~s}$. To identify the optimal concentration of dopamine, we established a dose-response curve for bath application of dopamine (Fig. 2G-I), starting with the lowest concentration of $3 \mu \mathrm{M}$ dopamine and increasing stepwise up to $1000 \mu \mathrm{M}$. We monitored the amount of responding astrocytes for every concentration. It became apparent that using $3 \mu \mathrm{M}$ dopamine $(\mathrm{n}=9)$ none of the astrocytes showed any change in intracellular calcium, while at $10 \mu \mathrm{M}$ dopamine $(n=41)$ one of 41 cells displayed a small calcium response. When using $30 \mu \mathrm{M}$ dopamine $(\mathrm{n}=86), 41.6 \%$ of the astrocytes showed a response. At $100 \mu \mathrm{M}$ dopamine $(\mathrm{n}=86)$ and above, every monitored astrocyte generated a prominent calcium elevation, indicating that $100 \mu \mathrm{M}$ dopamine is sufficient to activate all astrocytes containing dopamine receptors. Furthermore, using a concentration of $100 \mu \mathrm{M}$ is consistent with the experimentally determined $\mathrm{EC}_{50}$ of $76 \mu \mathrm{M}$ dopamine (Fig. $2 \mathrm{H}$ ).

Dopamine-induced calcium transients are independent of neuronal influence and mediated by internal calcium stores. The former experiments were performed in the presence of TTX to suppress action potential firing and hence indirect effects by neurons. However, it cannot be excluded that dopamine elicited action potential-independent local calcium rises in neurons that could lead to release of neurotransmitters such as glutamate and GABA. Since glutamate and GABA have been shown to trigger calcium signals in olfactory bulb astrocytes ${ }^{22,24}$, indirect neuronal effects might contribute to the calcium transients in astrocytes evoked by dopamine application. To elucidate whether dopamine-evoked neurotransmitter release contributed to the calcium transients in astrocytes, we investigated dopamine-induced calcium transients in synaptic isolation. We first tested whether repetitive application of dopamine results in rundown of the calcium response, e.g. due to receptor desensitization. After multiple applications of dopamine, a rundown of the dopamine-induced calcium transients could be observed (Fig. 3A). Compared to the first application, the second application evoked calcium transients that were reduced by $8.0+/-4.6 \%(\mathrm{n}=79 ; \mathrm{p}<0.001)$, whereas calcium transients evoked by the third application were attenuated by $21.6+/-3.4 \%(\mathrm{n}=79 ; \mathrm{p}<0.001$; Fig. $3 \mathrm{~A}, \mathrm{C})$. We then compared responses evoked by dopamine application either in the presence of TTX $(1 \mu \mathrm{M}$; Suppl. Fig. 1$)$ or in a mix of GABAergic, glutamatergic 

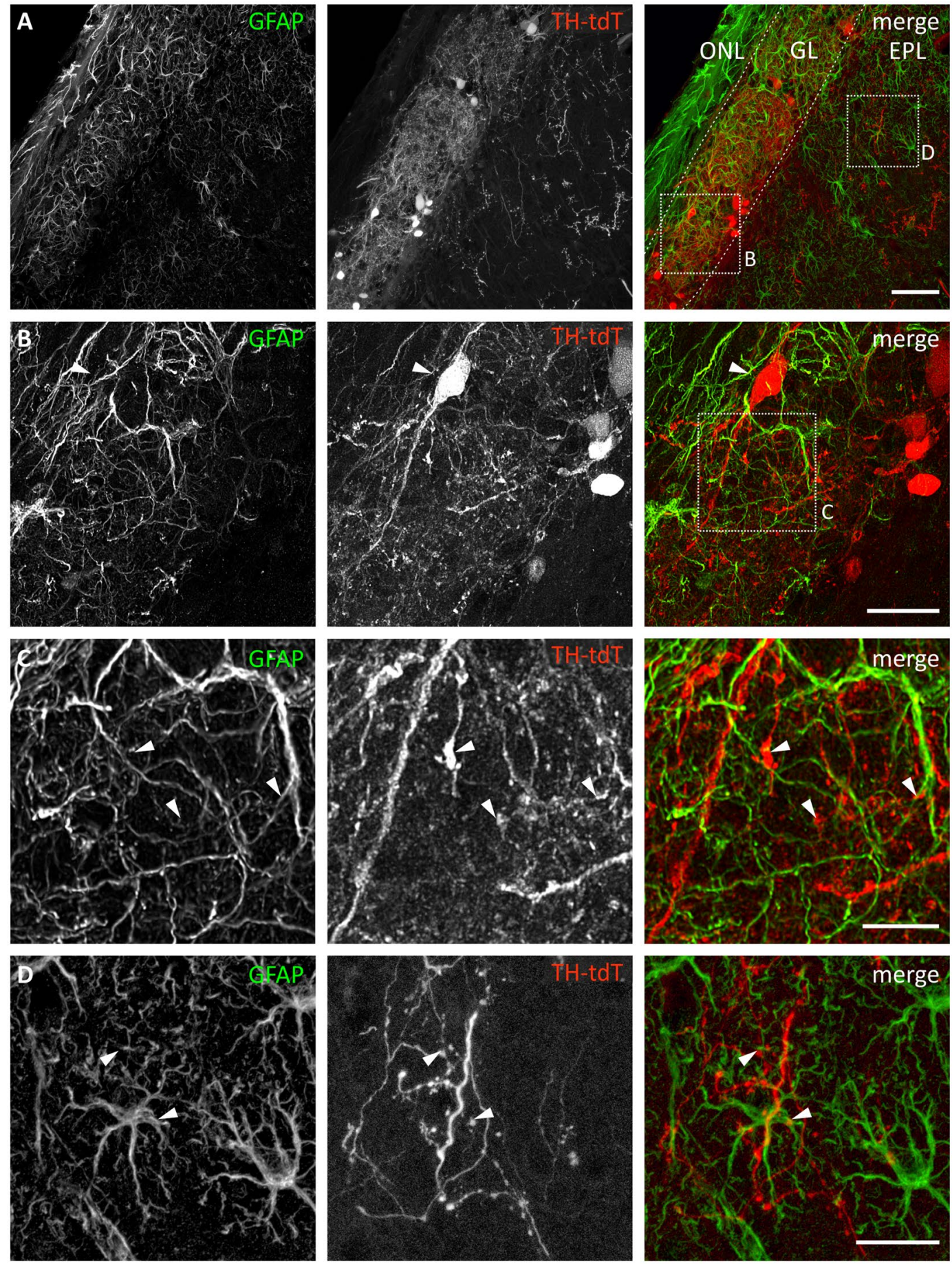

Figure 1. Distribution of astrocytes and tyrosine hydroxylase-expressing neurons in the olfactory bulb. (A) GL, glomerular layer; ONL, olfactory nerve layer. Anti-GFAP staining (green) shows astrocytes. Cell bodies of astrocytes are located in the GL and EPL. $\mathrm{TH}^{+}$neurons are labeled by tdTomato in THCre $\times$tdTomato $^{\mathrm{fl} /}$ ${ }^{\mathrm{fl}}$ mice (red) and are located mainly in the GL, but single neurons expressing tdTomato can be found in the EPL. Scale bar: $50 \mu \mathrm{m}$. (B) Magnified view from A, highlighting an interglomerular connecting short axon cell (arrowhead) in close proximity to astrocyte processes. Scale bar: $20 \mu \mathrm{m}$. (C) Magnified view from B, highlighting short axon cell dendrites, varicosities (arrowheads) and astrocytic processes in detail. Scale bar: $10 \mu \mathrm{m}$. (D) Magnified view from A, highlighting localization of astrocytes and $\mathrm{TH}^{+}$varicosities (arrowheads). Scale bar: $20 \mu \mathrm{m}$.

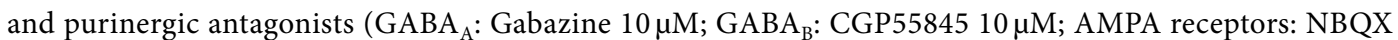
$10 \mu \mathrm{M}$; NMDA receptors: D-APV $50 \mu \mathrm{M}$; mGluR $_{5}$ : MPEP $2 \mu \mathrm{M} ; \mathrm{P}_{2} \mathrm{Y}_{1}$ : MRS2179 $50 \mu \mathrm{M} ; \mathrm{A}_{2 \mathrm{~A}}$ : ZM241385 $0.5 \mu \mathrm{M}$; sodium channels: TTX $1 \mu \mathrm{M}$ ) with the corresponding control application in the absence of receptor antagonists to assess the contribution of these receptors to the dopamine-evoked response (blockermix, BM; Fig. 3B,C). In 
A

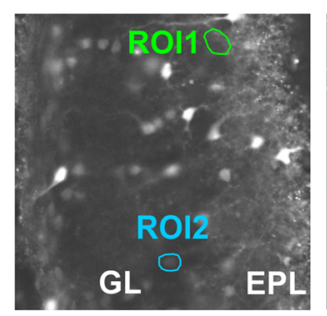

C

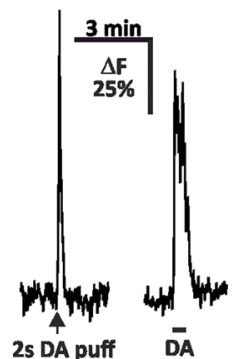

G

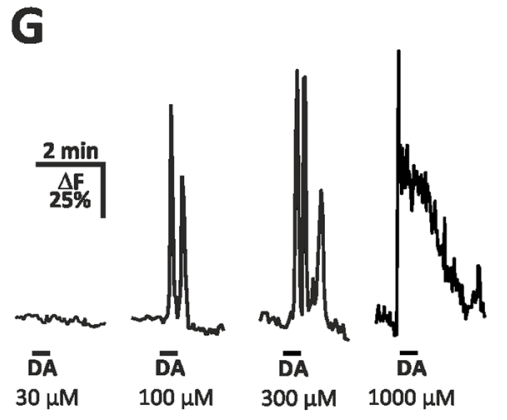

$100 \mu \mathrm{M}$ ADP

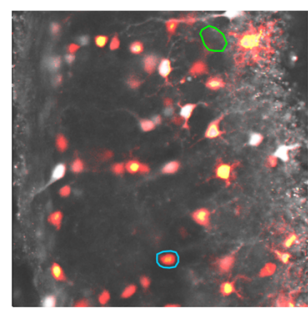

D

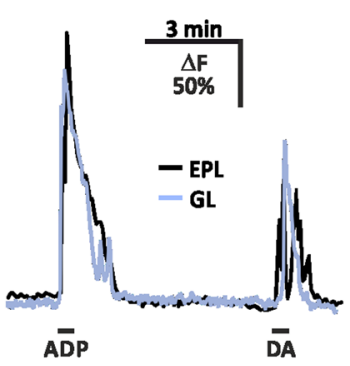

$50 \mathrm{mM} \mathrm{K}^{+}$

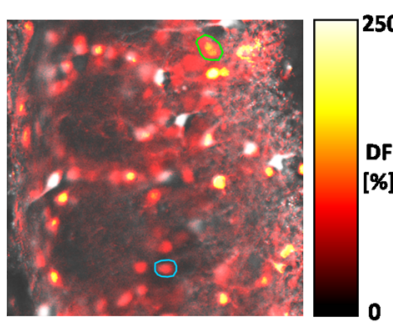

E

- Dopaminergic response
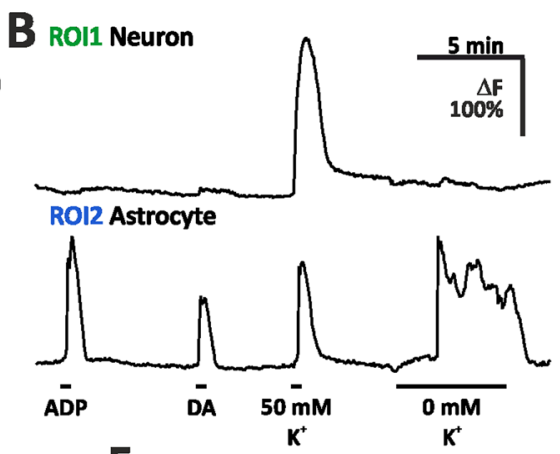

$\mathbf{F}$
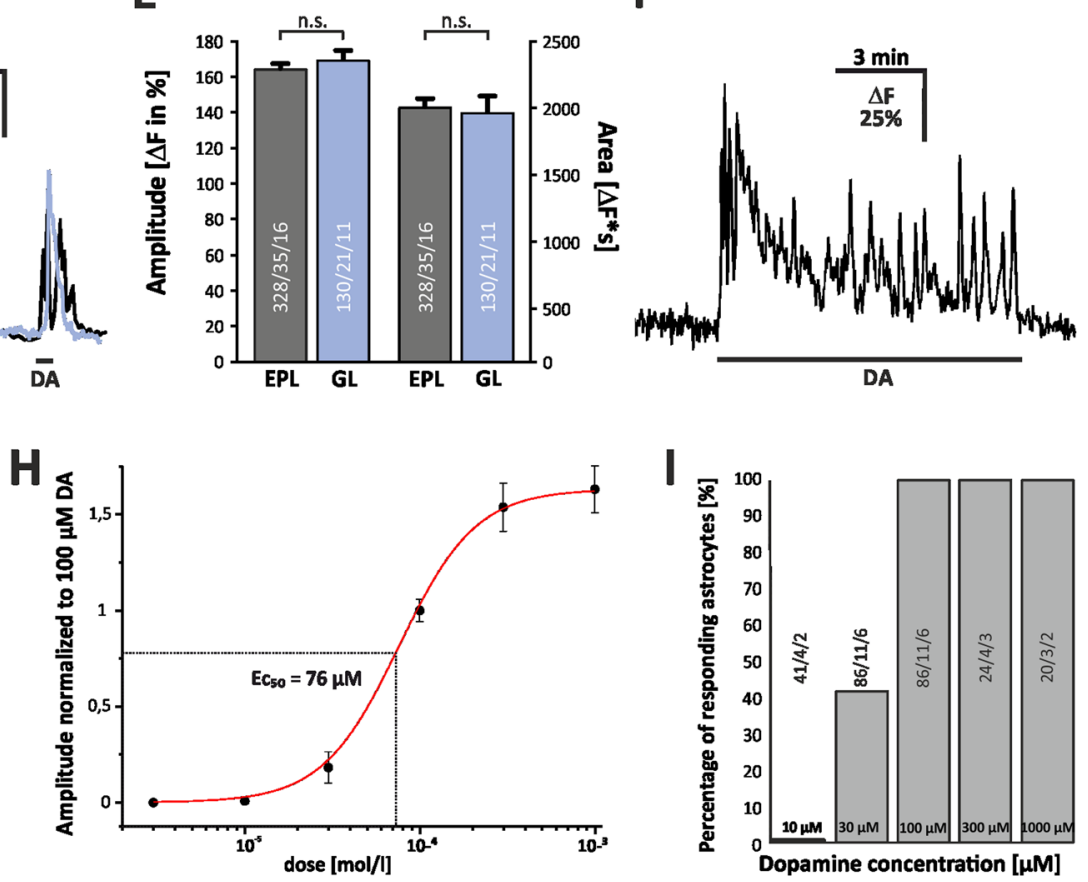

Figure 2. Dopamine-triggered calcium response in olfactory bulb (OB) astrocytes. (A) Fluo-8 staining of acute $\mathrm{OB}$ slices with example ROIs shown in idle state (left), in the presence of $100 \mu \mathrm{M}$ ADP (middle) and high potassium ACSF (right). (B) Example traces of cells that are considered to be a neuron (ROI1) and an astrocyte (ROI2). (C) Dopamine-induced calcium responses of astrocytes by short pressure application $(500 \mu \mathrm{M}$, left $)$ and bath application $(100 \mu \mathrm{M}$, right). (D) Calcium responses of astrocytes evoked by application of $\operatorname{ADP}(30 \mathrm{~s}, 100 \mu \mathrm{M})$ and dopamine $(\mathrm{DA} ; 30 \mathrm{~s}, 100 \mu \mathrm{M})$ in both EPL (black trace) and GL (blue trace). (E) Averaged amplitudes (left bars) and area (right bars) of DA-induced calcium responses in EPL and GL (error bars: SEM). Sample size as specified in the bars: cells/slices/animals. n.s.: not significant. (F) Calcium response of an astrocyte monitored during a 10-min application of DA $(100 \mu \mathrm{M})$. (G) Calcium responses induced by application of dopamine at different concentrations. (H) Dose-response curve of dopamine-induced astroglial calcium responses (area), normalized to application of $100 \mu \mathrm{M} \mathrm{DA}(+/-\mathrm{SEM})$. (I) Percentage of astrocytes responding to dopamine application.

the presence of the blocker mix, the dopamine-induced calcium transient was slightly decreases by $12.1+/-$ $3.6 \%(\mathrm{n}=55 ; \mathrm{p}<0.05)$ in amplitude and $9.7+/-7.4 \%(\mathrm{n}=55 ; \mathrm{p}<0.05)$ in area as compared to the second application of the control experiment (rundown). No significant differences between the values in the control experiments and in experiments using the blockermix were found, indicating that the neuronal contribution to dopamine-evoked calcium transients in $\mathrm{OB}$ astrocytes is negligible (Fig. 3C).

To test whether dopamine-evoked calcium transients are mediated by calcium release from internal stores, we applied dopamine before and after calcium stores were depleted by incubation with $20 \mu \mathrm{M}$ cyclopiazonic acid (CPA). Depletion of internal stores led to a long-lasting elevation in intracellular calcium and suppressed dopamine-evoked calcium responses. The mean amplitude of dopamine-induced calcium transient was reduced by $93.8+/-2.5 \%(\mathrm{n}=50 ; \mathrm{p}<0.001)$ and the area by $88.2+/-2.9 \%(\mathrm{n}=50 ; \mathrm{p}<0.001)($ Fig. $4 \mathrm{~A}, \mathrm{D})$, indicating that the calcium rise is mainly mediated by internal calcium release. The canonical pathways downstream of dopamine receptors are stimulation or inhibition of adenylate cyclase via $G \alpha_{s}$ and $G \alpha_{i}$ proteins, however, intracellular signaling via $\mathrm{G \alpha}_{\mathrm{q} / 11}$ proteins and phospholipase $\mathrm{C}$ (PLC) has also been described by both $\mathrm{D}_{1}$-class and $\mathrm{D}_{2}$-class dopamine receptors ${ }^{25-29}$. To ascertain whether the calcium rise depends on the $\mathrm{PLC} / \mathrm{IP}_{3}$ signaling pathway, we 

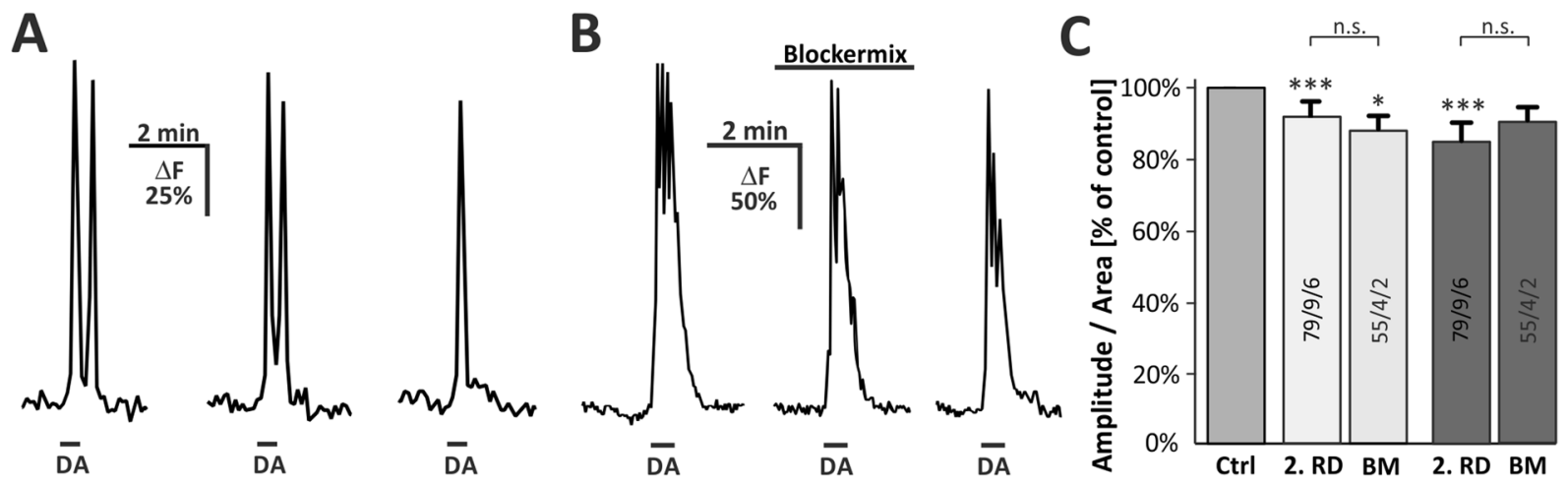

Figure 3. Dopamine-induced calcium transients in $\mathrm{OB}$ astrocytes in synaptic isolation. (A) Example of multiple applications of DA $(100 \mu \mathrm{M})$ with a 10-min interval. (B) Calcium transients were not affected in presence of GABAergic, glutamatergic und purinergic antagonists (Blockermix contains: NBQX $10 \mu \mathrm{M}, \mathrm{D}-\mathrm{APV}$ $50 \mu \mathrm{M}$, gabazine $10 \mu \mathrm{M}$, CGP55845 $10 \mu \mathrm{M}$, MPEP $2 \mu \mathrm{M}$, MRS2179 $50 \mu \mathrm{M}$, ZM241385 0.5 $\mu \mathrm{M}$, TTX $1 \mu \mathrm{M})$.

(C) Normalized averaged amplitudes (light grey, $+/$-SEM) and area (dark grey, $+/-$ SEM) of calcium responses under control conditions and after application of Blockermix (BM). Results of BM are additionally compared to rundown (RD) experiment as depicted in (A) (error bars: SEM). $* \mathrm{P}<0.05, * * \mathrm{P}<0.01, * * * \mathrm{P}<0.005$.

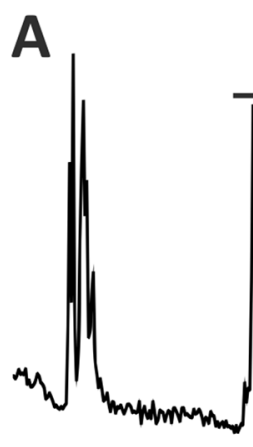

$\overline{\mathrm{DA}}$

C

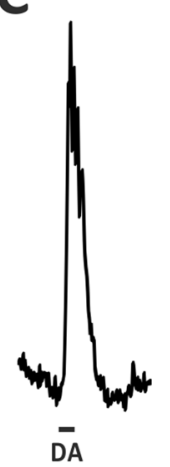

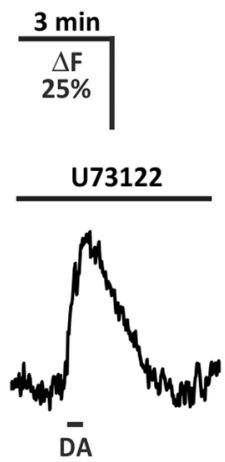

CPA
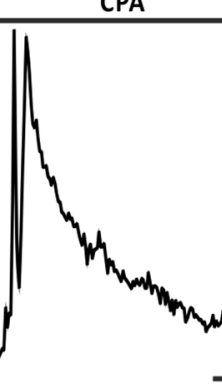

$\overline{\mathrm{DA}}$

D

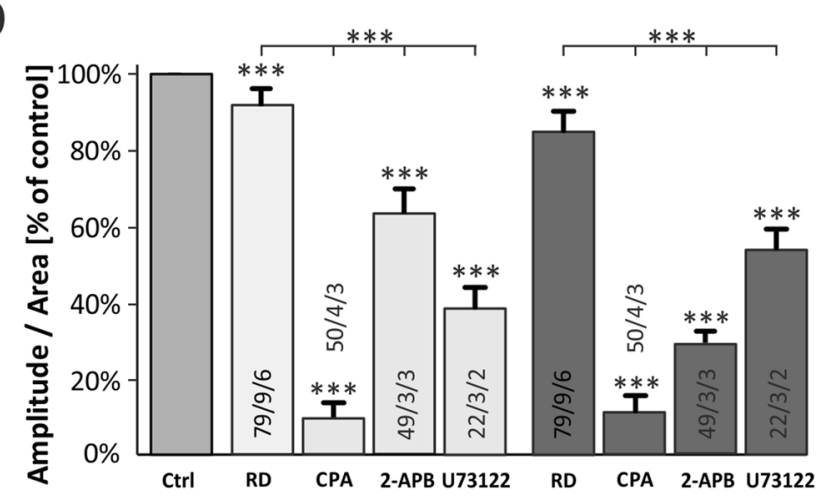

Figure 4. Internal calcium release mediates dopamine-induced calcium transients in OB astrocytes. (A) Dopamine-induced calcium transients are entirely suppressed in the presence of SERCA inhibitor cyclopiazonic acid $(\mathrm{CPA}, 20 \mu \mathrm{M})$. (B) Calcium transients are partly diminished in the presence of $\mathrm{IP}_{3}$ receptor antagonist 2-APB $(50 \mu \mathrm{M})$. (C) Attenuated calcium transients in the presence of PLC inhibitor U73122 $(50 \mu \mathrm{M})$. (D) Normalized averaged amplitudes (left, $+/-$ SEM) and area (right, $+/-$ SEM) of calcium responses under control conditions and after application of CPA, 2-APB and U73122. Results are additionally compared to rundown $(\mathrm{RD})$ experiment as depicted in Fig. $3 \mathrm{~A}$. $* \mathrm{P}<0.05, * * \mathrm{P}<0.01, * * * \mathrm{P}<0.005$.

applied dopamine in the presence of the $\mathrm{IP}_{3}$ receptor antagonist 2-APB (Fig. 4B). A relatively low concentration of $50 \mu \mathrm{M} 2-\mathrm{APB}$ was used, since higher concentrations activate transient receptor potential channels TRPV and lead to calcium oscillations in $\mathrm{OB}$ astrocytes ${ }^{24} .50 \mu \mathrm{M} 2$-APB attenuated dopamine-induced calcium responses by $36.8+/-6.6 \%(n=49 ; \mathrm{p}<0.001)$ in amplitude and $71.3+/-3.1 \%(\mathrm{n}=49 ; \mathrm{p}<0.001)$ in area, suggesting the involvement of $\mathrm{IP}_{3}$ receptors (Fig. 4B,D). In addition, the sustained phase of the calcium response was entirely 
blocked by 2-APB (Fig. 4B). In order to obtain further indication for the participation of this signaling pathway, dopamine was applied after 30 minutes of incubation with the PLC inhibitor U73122 $(50 \mu \mathrm{M})$. Under these conditions, the dopamine-induced calcium response was reduced by $61.6+/-5.2 \%(\mathrm{n}=22 ; \mathrm{p}<0.001)$ in amplitude and by $46.2+/-5.0 \%(\mathrm{n}=22 ; \mathrm{p}<0.001)$ in area (Fig. 4C,D). Interestingly, the dopamine-evoked calcium transient appeared to be sustained in the presence of U73122 as compared to the control response (Fig. 4C).

Dopamine-induced calcium transients depend on D1 and D2-like receptors. To accomplish the characteristics of astrocytic dopamine signaling, we were interested which class of dopamine receptor is expressed and mediates calcium signaling in $\mathrm{OB}$ astrocytes. Therefore, we tested the effects of $\mathrm{D}_{1}$-class as well as $\mathrm{D}_{2}$-class dopaminergic receptor antagonists on dopamine-induced calcium transients. In the presence of the $\mathrm{D}_{1}$-antagonist SCH23390, the dopamine-induced calcium transient was reduced by $47.2+/-5.0 \%(\mathrm{n}=54$; $\mathrm{p}<0.001)$ in amplitude and $64.1+/-6.2 \%(\mathrm{n}=54 ; \mathrm{p}<0.001)$ in area (Fig. $5 \mathrm{~A}, \mathrm{~B})$. The $\mathrm{D}_{2}$-antagonist sulpiride resulted in an attenuation of the dopamine-induced calcium transient by $37.9+/-4.1 \%(\mathrm{n}=124 ; \mathrm{p}<0.001)$ in amplitude and $48.2+/-6.9 \%(\mathrm{n}=124 ; \mathrm{p}<0.001)$ in area (Fig. 5C,D). In the presence of both SCH23390 and sulpiride, dopamine-dependent calcium signaling was nearly completely abolished with a reduction by $85.9+/-$ $2.8 \%(\mathrm{n}=96 ; \mathrm{p}<0.001)$ in amplitude and 93.1+/ $-1.7 \%(\mathrm{n}=96 ; \mathrm{p}<0.001)$ in area, respectively (Fig. 5E,F). In all experiments, the antagonist-dependent decrease in calcium rise was at least partly reversible. These results indicate a participation of both $\mathrm{D}_{1}$-class and $\mathrm{D}_{2}$-class receptors in dopamine-induced calcium signaling in $\mathrm{OB}$ astrocytes.

\section{Discussion}

Dopamine induces calcium transients in olfactory bulb astrocytes. In the present study we showed that dopamine induced an increase in intracellular calcium concentration in olfactory bulb astrocytes in situ. We could demonstrate that the dopamine-evoked calcium rise was entirely blocked in the presence of SERCA inhibitor CPA, indicating that dopamine triggered calcium release from internal stores such as the endoplasmic reticulum (ER). The most common mechanism to liberate calcium from the ER is the $\mathrm{PLC}_{\mathrm{IP}}$ signaling pathway, which has previously been shown in $\mathrm{OB}$ astrocytes to be activated by $\mathrm{P} 2 \mathrm{Y}_{1}$ receptors, $\mathrm{A}_{2 \mathrm{~A}}$ receptors and $\mathrm{mGluR}_{5}{ }^{21,30}$. Although dopamine receptors are mainly considered to be linked to adenylate cyclases, several instances have shown stimulation of PLC by both $\mathrm{D}_{1}$-class and $\mathrm{D}_{2}$-class dopamine receptors (reviewed by Beaulieu et al. $\left.{ }^{14}\right)$. Hence, it is likely that dopamine releases calcium from the ER by stimulation of PLC. Based on this assumption, we performed experiments in the presence of phospholipase C inhibitor U73122 and the IP $\mathrm{IP}_{3}$ receptor antagonist $2-\mathrm{APB}$, which both resulted in a considerable decrease in dopamine-induced calcium rise. Furthermore, the kinetics of the calcium response was altered in the presence of both 2-APB and U73122. The property of 2-APB acting not only as an $\mathrm{IP}_{3}$ receptor antagonist, but also as an inhibitor of store-operated calcium entry (SOCE), may provide an explanation for the rapid decay of the calcium rise after reaching its peak, since inhibition of SOCE channels suppresses the late phase of the calcium response ${ }^{31}$. This result may be considered as a first indication of the involvement of SOCE in dopamine-induced calcium transients in astrocytes. In contrast, in the presence of the PLC inhibitor U73122, despite a significant reduction in mean amplitude, a prolongation of the dopamine-induced calcium transient could be observed. This might be due to the U73122-mediated attenuation of the PKC signaling pathway, which acts downstream of PLC activation as a negative feedback mechanism to terminate calcium elevations evoked by $\mathrm{G}$ protein-coupled receptors ${ }^{32,33}$. Our results suggest major contribution of the $\mathrm{PLC} / \mathrm{IP}_{3}$ pathway to dopaminergic calcium responses in OB astrocytes, however, both U73122 and 2-APB failed to entirely block dopamine-induced calcium transients. We cannot exclude that the concentrations of the compounds at their targets were not sufficient to totally block PLC-mediated $\mathrm{IP}_{3}$ receptor activation, since U73122 does not easily diffuse within tissue and, in order to avoid activation of TRPV channels, the concentration of 2 -APB could not be raised to values needed for complete block of $\mathrm{IP}_{3}$ receptors ${ }^{24}$.

$D_{1}$ - and $D_{2}$-class receptors mediate calcium signaling in olfactory bulb astrocytes. The dopamine-induced calcium elevation was decreased by both $\mathrm{D}_{1}$ - and $\mathrm{D}_{2}$-class receptor antagonists, thus both classes of dopamine receptors appear to contribute to the dopamine-evoked calcium transients. This is in line with observations suggesting that both $\mathrm{D}_{1}$ - and $\mathrm{D}_{2}$-class receptors elicit release of $\mathrm{IP}_{3}$ and calcium signaling in astrocytes ${ }^{25-29}$. Whether this effect in $\mathrm{OB}$ astrocytes is mediated by $\mathrm{D}_{1}-\mathrm{D}_{2}$ heteromers, as shown in striatal neurons ${ }^{34}$, or by independent $\mathrm{D}_{1}$ and $\mathrm{D}_{2}$ receptors is not known and needs further investigation. In contrary to our results, studies in the hippocampus and ventral midbrain have shown that activation of $\mathrm{D}_{2}$ receptors leads to a decrease in cytosolic calcium, whereas $\mathrm{D}_{1}$ receptors mediate a calcium rise $\mathrm{e}^{29,35}$. The $\mathrm{D}_{2}$-class receptor-mediated decrease in calcium in hippocampal astrocytes presumably results from modulation of L-type voltage-gated calcium channels ${ }^{29}$, which has also been shown in nucleus accumbens neurons ${ }^{36}$. Apparently, this mechanism does not exist in astrocytes of the olfactory bulb. However, it must me mentioned that, due to the limitations of two-dimensional confocal imaging and lack of visibility of small cell processes after bulk loading of calcium indicators, it is possible that other small-scaled but functionally important calcium signals in fine astrocyte processes may have been unexploited. Furthermore, in comparison to the work of Jennings et al. ${ }^{29}$, there are some considerable differences in experimental design, such as our method of application differed in terms of duration. While Jennings et al. used a puff application of 3 minutes and bath application of 10 minutes in most trials, it was sufficient to confine the dopamine application to 2 seconds (puff application) and 30 seconds (bath application) in our study, suggesting a high dopamine sensitivity in astrocytes of the $\mathrm{OB}$, but only moderate sensitivity in the hippocampus. This is confirmed by the long delay in onset of the calcium response often seen in hippocampal astrocytes $^{29}$. The dopamine sensitivity of OB astrocytes might even be underestimated, since bulk-loading of calcium indicators results in significantly smaller calcium-dependent fluorescence changes compared to loading single cells (and gap junction-coupled cells) via a patch pipette ${ }^{29}$. 

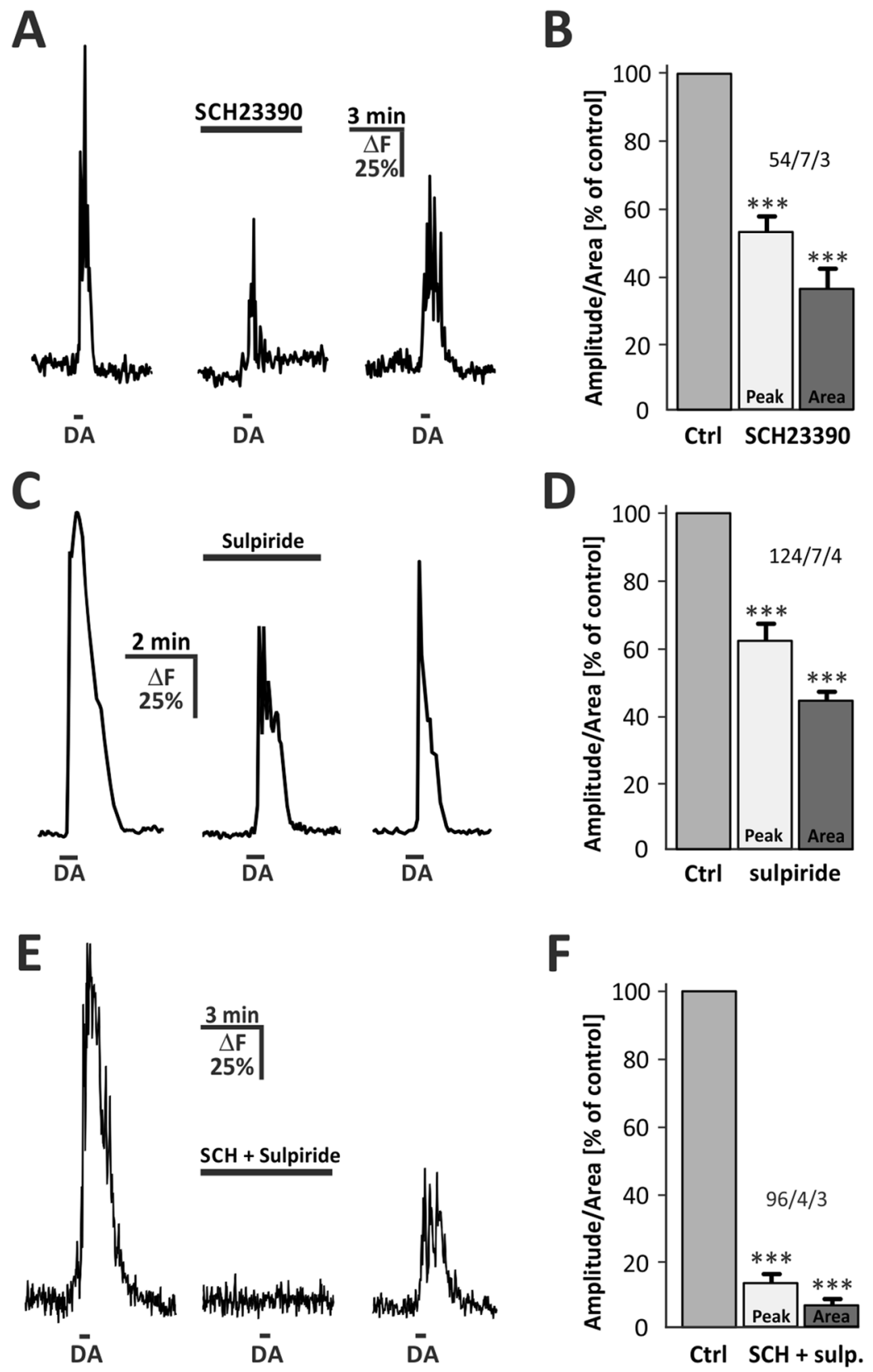

Figure 5. Effect of DA receptor antagonists on dopamine-induced calcium signaling in OB astrocytes. (A) Calcium transients evoked by DA $(30 \mathrm{~s}, 100 \mu \mathrm{M})$ where reduced in amplitude and integral in the presence of D1-class antagonist SCH23390 $(50 \mu \mathrm{M})$. (B) Normalized averaged amplitude and area of calcium responses in presence of SCH23390. (C) Calcium transients where reduced in the presence of D2-class antagonist sulpiride $(50 \mu \mathrm{M})$. (D) Normalized averaged amplitude and area of calcium responses in presence of sulpiride. (E) Effect of both SCH23390 and sulpiride on dopamine-evoked calcium responses. (F) Normalized averaged amplitude and area $(+/-\mathrm{SEM})$ of calcium responses in the presence of both antagonists. $* \mathrm{P}<0.05, * * \mathrm{P}<0.01$, $* * * \mathrm{P}<0.005$.

Although the localization of tyrosine hydroxylase and thus dopamine-containing neuronal elements has its highest density in the glomerular layer (Fig. $1 \mathrm{~A})^{10}$, the distribution of the $\mathrm{D}_{1}$-receptor is widely spread over all $\mathrm{OB}$ layers except of the nerve layer ${ }^{37-42}$. This indicates a functional role of dopamine in the entire OB, including the glomerular layer as well as in external plexiform layer, which is consistent with our results. The distribution of the $\mathrm{D}_{2}$ receptor has its highest density in the GL and nerve layer, while $\mathrm{D}_{2}$ receptor expression in the EPL is sparse $^{40,43-45}$. Despite that, the dopamine-induced calcium transients where strongly reduced in the presence of $\mathrm{D}_{2}$ antagonist sulpiride in both the GL and EPL, indicating expression of $\mathrm{D}_{2}$ receptors in astrocytes of the EPL. Previous studies by Pignatelli et al. ${ }^{37}$ showed that during the process of maturation of adult-born dopaminergic neurons, two populations of $\mathrm{TH}^{+}$neurons outside the glomerular layer exist. One of these populations represents dopaminergic neurons that undergo the last step in maturation and can be found in the mitral cell layer and 
external plexiform layer ${ }^{37}$. These cells project numerous processes within the EPL, suggesting release of dopamine not only in the GL but also in deeper layers. As shown in Fig. 1, our histological analysis of TH-expressing neurons supports this observation. Hence, astrocytes in the EPL might detect dopamine released by immature adult-born neurons with calcium signaling and, in turn, provide growth factors and components of the extracellular matrix to support neuronal maturation as shown, e.g., in the cerebellum ${ }^{46}$.

Putative functional roles of dopamine-evoked calcium signaling in astrocytes. It is well known that astrocytes are involved in a variety of processes in the CNS. Apart from well-established supportive astrocytic functions such as metabolic supply and potassium homeostasis, more recent studies revealed that astrocytes are tightly integrated into neural networks in a functional manner. As a result of astroglial calcium excitability, astrocytes are capable of "gliotransmission", i.e. release of transmitters which can lead to signaling to neighboring neurons and blood vessels $s^{47,48}$. In the main olfactory bulb, several studies provided evidence for important functions of astrocytes, e.g. gliotransmission ${ }^{49}$. Kozlov et al. demonstrated that astrocytes in the rat olfactory bulb release two classical transmitters, GABA and glutamate, upon mechanical stimulation to evoke synchronous currents in mitral and granule cells ${ }^{50}$. Another gliotransmitter released by OB astrocytes is ATP that is degraded to adenosine, a potent neuromodulator in the $\mathrm{OB}^{23,51}$. In mitral cells, adenosine activates two-pore domain potassium channels and inhibits presynaptic calcium channels, resulting in reduced spontaneous firing and attenuated reciprocal dendro-dendritic inhibition ${ }^{52,53}$. OB astrocytes also play a key role in neurovascular coupling, since it has been shown that the physiological activation of olfactory sensory neurons by odors reliably triggers calcium increases in astrocyte processes in the glomerular layer and subsequent dilation of blood vessels ${ }^{30,54}$. Neurovascular coupling is not restricted to the GL, since astrocytes transmit panglial calcium waves to olfactory ensheathing glial cells in the nerve layer, which there contribute to regulation of blood vessel diameter ${ }^{55,56}$. Which role dopaminergic calcium signaling in astrocytes plays in neuronal performance and neurovascular coupling in the $\mathrm{OB}$ is not known so far and needs further investigation. However, tuning of olfactory information processing and odor perception by neuromodulators such as dopamine, noradrenaline, acetylcholine and serotonin has moved into the focus of research on olfaction, in particular in recent years ${ }^{23,57-59}$, and it is becoming increasingly clear that astrocytes have to be considered to take actively part in these processes. This hypothesis appears to be supported by findings showing interactions of dopamine and astrocytes in other regions of the CNS, such as ventral midbrain and hippocampus ${ }^{29,35}$.

\section{Methods}

Animals used for slice preparation. Naval Medical Research Institute (NMRI) outbred mice from postnatal day 7 (p7) to p21 were used for calcium imaging experiments. The mice were bred in the institute's animal facility at the University of Hamburg. This study was carried out in accordance with the recommendations of the European Union's and local animal welfare guidelines. Mice were anesthetized using isoflurane (5\% mixed with $1 \mathrm{~L} / \mathrm{min}_{2}$ ) and decapitated before using for experiments. The permission to despatch mice for the purpose of organ extraction was obtained by the Hamburg Authority of Health and Consumer Protection (GZ G21305/59100.33; Behörde für Gesundheit und Verbraucherschutz, Hamburg, Germany). According to the local laws, an additional ethical approval for animal experiments in the current study was not required. Olfactory bulb slices were prepared as described before ${ }^{60}$. Slices were quickly transferred into a chilled artificial cerebrospinal fluid (ACSF, see below). $200 \mu \mathrm{m}$ thick horizontal slices of the bulbs were cut using a vibratome (Leica VT1200S, Bensheim, Germany). Brain slices were stored in ACSF for $30 \mathrm{~min}$ at $30^{\circ} \mathrm{C}$ and $15 \mathrm{~min}$ at room temperature before starting experiments. ACSF was continuously gassed with carbogen (95\% O2/5\% CO2; buffered to $\mathrm{pH} 7.4$ with CO2/bicarbonate).

Solutions and chemicals. The standard ACSF for acute brain slices contained (in mM): $\mathrm{NaCl} 125$, $\mathrm{KCl} 2.5, \mathrm{CaCl}_{2} 2, \mathrm{MgCl}_{2}$ 1, D-glucose 25, $\mathrm{NaHCO}_{3} 26, \mathrm{NaHPO}_{4}$ 1.25, gassed during the entire experiment with carbogen to adjust the $\mathrm{pH}$ to 7.4. MRS 2179 (2'-deoxy-N6-methyladenosine $3^{\prime}, 5^{\prime}$-bisphosphate tetrasodium salt) and ZM241385 (4-(2-[7-Amino-2-(2-furyl)[1, 2, 4] triazolo[2, 3-a] [1, 3, 5] triazin-5-ylamino] ethyl)phenol) was obtained from Tocris (Bristol, UK). D-APV (D-2-amino-5-phosphonopentanoic acid), NBQX (2, 3-dioxo-6-nitro-1, 2, 3, 4-tetrahydrobenzo[f] quinoxaline-7-sulfonamide), gabazine (6-Imino3-(4-methoxyphenyl)-1(6H)-pyridazinebutanoic acid hydrobromide), TTX (tetrodotoxin, Octahydro12-(hydroxymethyl)-2-imino-5, 9:7, 10a-dimethano-10a $H$ - $[1,3]$ dioxocino $[6,5-d]$ pyrimidine-4, 7, 10, 11, 12-pentol + citrate buffer), CPA (cyclopiazonic acid; $(6 \mathrm{a} R, 11 \mathrm{aS}, 11 \mathrm{~b} R)$-10-acetyl-2, 6, 6a, 7, 11a, 11b-hexahydro-11-hydroxy-7, 7-dimethyl-9H-pyrrolo[1', 2':2, 3] isoindolo[4, 5, 6-cd]indol-9-one, SCH23390 $((\mathrm{R})-(+)-7$-chloro-8-hydroxy-3-methyl-1-phenyl-2, 3, 4, 5-tetrahydro-1H-3-benzazepine) and sulpiride $((R, S)$ ( \pm )-5-Aminosulfonyl- $N$-[(1-ethyl-2-pyrrolidinyl)methyl]-2-methoxybenzamide) were obtained from Abcam (Cambridge, United Kingdom). All substances were stored as stock solutions according to the manufacturers' description.

Immunohistochemistry. Immunohistochemistry on olfactory bulbs of TH-Cre (B6.Cg-7630403G23Rik $g($ Th-cre $) 1 T m d / J) \times$ tdTomato $^{\mathrm{f} / \mathrm{fl}}$ mice $(\mathrm{P} 28)$ was performed as described ${ }^{22,61,62}$. These mice express the red fluorescent reporter tdTomato under control of Cre recombinase, which is expressed only by cells with active tyrosine hydroxylase promoter. After dissection, the olfactory bulbs were kept for $1 \mathrm{~h}$ at room temperature (RT) in formalin (4\% paraformaldehyde in PBS, $\mathrm{pH}$ 7.4). Subsequently, $120 \mu \mathrm{m}$ thick sagittal slices were prepared with a vibratome (VT1000S, Leica, Nussloch, Germany) and incubated for $1 \mathrm{~h}$ in blocking solution (10\% normal goat serum [NGS], $0.5 \%$ Triton X-100 in PBS) at RT. Afterwards, the slices were incubated for $48 \mathrm{~h}$ at $4{ }^{\circ} \mathrm{C}$ with a chicken anti-GFAP antibody (Synaptic Systems, Göttingen, Germany; 1:1000). The antibody was diluted in 1\% NGS, $0.05 \%$ Triton X-100 in PBS. Slices were incubated in PBS with the goat anti-chicken Alexa 488 secondary 
antibody (Abcam; 1:1000) for $24 \mathrm{~h}$ at $4^{\circ} \mathrm{C}$. Subsequently, the slices were mounted on slides using self-hardening embedding medium (Immu-Mount, Thermo Fisher). Immunohistological stainings were analyzed using a confocal microscope (C1 Eclipse, Nikon, Düsseldorf, Germany). Confocal images were deconvolved using a theoretical point-spread function (Huygens, SVI, Hilversum, Netherlands) and enhanced for brightness and contrast using Image and Adobe Photoshop CS2.

Calcium imaging. Slices were incubated with the membrane-permeable form of the calcium indicator Fluo- 8 (Fluo-8-AM; $2 \mu \mathrm{M}$ in ACSF) made from a $2 \mathrm{mM}$ stock solution (dissolved in DMSO and $20 \%$ pluronic acid) for $30 \mathrm{~min}$. Brain slices were then placed in the recording chamber and fixed with a U-shaped platinum wire with nylon strings. Brain slices were continuously superfused at a rate of $2 \mathrm{ml} / \mathrm{min}$ with ACSF that was gassed with carbogen $\left(95 \mathrm{O}_{2} / 5 \% \mathrm{CO}_{2}\right)$. Bath perfusion with ACSF was accomplished using a peristaltic pump (Vario, Ismatec, Germany). Drugs were applied via the perfusion system. If not stated otherwise, ACSF contained $1 \mu \mathrm{M}$ TTX to suppress neuronal activity. Changes in intracellular calcium levels in olfactory bulb astrocytes were recorded by confocal microscopy (C1 Eclipse, Nikon, Düsseldorf, Germany). An excitation laser wavelength of $488 \mathrm{~nm}$ and a frame rate of $0.75 \mathrm{fps}$ were used and the fluorescence was collected through a $500-530 \mathrm{~nm}$ bandpass filter.

Data analysis and statistic. The data were evaluated with Nikon EZ-C1 Viewer (Nikon) and statistical tests have been applied with Origin Pro 9.1 (OriginLab Corporation, Northampton, USA). To analyze changes of the calcium level in astrocytes, cell somata were marked as regions of interests (ROIs). Cells located in the glomerular layer and external plexiform layer that showed a calcium response to ADP were identified as astrocytes ${ }^{21,22}$. This method of cell identification has been verified by using $\mathrm{K}^{+}$-free and $50 \mathrm{mM} \mathrm{K}^{+}$-containing ACSF, in which $\mathrm{K}^{+}$was exchanged for $\mathrm{Na}^{+}$. Astrocytes, but not neurons, respond to $\mathrm{K}^{+}$-free ACSF with calcium signaling ${ }^{31}$. The astrocytic calcium elevations have been observed in both glomerular layer and external plexiform layer, without a significant difference in amplitude or duration, therefore most of the results in the present study are pooled data of both layers. To evaluate changes of calcium levels over time, Fluo-8 fluorescence intensity (F) was recorded during the course of the experiment and normalized to the basal fluorescence intensity in absence of pharmacological stimuli. Changes in calcium are given by $\Delta \mathrm{F}$ as the percentage changes in fluorescence with respect to the basal fluorescence. Calcium responses were assessed as amplitude (baseline to peak) and area (integral of the curve from beginning of the response until baseline was reached again). All values are given as mean values $(+/-)$ standard error of the mean with " $n$ " representing the number of cells analyzed for a certain set of experiment. In the figures, sample size is given as "number of cells/number of brain slices/number of animals". The proof of statistical significance was done by Wilcoxon signed-rank test at an error probability $\mathrm{p}\left({ }^{*} \mathrm{p}<0.05 ; * * \mathrm{p}<0.01\right.$; $* * * \mathrm{p}<0.001)$. In case of independent data the Mann-Whitney-U test was applied. The dose-response curve was generated using the response to $100 \mu \mathrm{M}$ dopamine, a concentration used in all measurements analyzed for the dose-response relationship, as reference. The values of all responses to $100 \mu \mathrm{M}$ dopamine were averaged, resulting in $85.2+/-5.1 \% \Delta \mathrm{F}$, and $\Delta \mathrm{F}$ values of all individual cells were normalized to this value. Normalized values were pooled and the dose-response curve was generated using Origin Pro 9.1.

\section{Data availability}

All data are available from the authors upon request.

Received: 27 September 2019; Accepted: 30 December 2019;

Published online: 20 January 2020

\section{References}

1. Schultz, W. Multiple dopamine functions at different time courses. Annu. Rev. Neurosci. 30, 259-288, https://doi.org/10.1146/ annurev.neuro.28.061604.135722 (2007)

2. Felten, D. L. \& Sladek, J. R. Jr. Monoamine distribution in primate brain V. Monoaminergic nuclei: anatomy, pathways and local organization. Brain Res. Bull. 10, 171-284, https://doi.org/10.1016/0361-9230(83)90045-x (1983).

3. Cave, J. W. \& Baker, H. Dopamine systems in the forebrain. Adv. Exp. Med. Biol. 651, 15-35 (2009).

4. Halasz, N., Johansson, O., Hokfelt, T., Ljungdahl, A. \& Goldstein, M. Immunohistochemical identification of two types of dopamine neuron in the rat olfactory bulb as seen by serial sectioning. J. Neurocytol. 10, 251-259 (1981).

5. McLean, J. H. \& Shipley, M. T. Postmitotic, postmigrational expression of tyrosine hydroxylase in olfactory bulb dopaminergic neurons. J. Neurosci. 8, 3658-3669 (1988).

6. Panzanelli, P., Fritschy, J. M., Yanagawa, Y., Obata, K. \& Sassoe-Pognetto, M. GABAergic phenotype of periglomerular cells in the rodent olfactory bulb. J. Comp. Neurol. 502, 990-1002, https://doi.org/10.1002/cne.21356 (2007)

7. Maher, B. J. \& Westbrook, G. L. Co-transmission of dopamine and GABA in periglomerular cells. J. Neurophysiol. 99, 1559-1564, https://doi.org/10.1152/jn.00636.2007 (2008).

8. Borisovska, M., Bensen, A. L., Chong, G. \& Westbrook, G. L. Distinct modes of dopamine and GABA release in a dual transmitter neuron. J. Neurosci. 33, 1790-1796, https://doi.org/10.1523/JNEUROSCI.4342-12.2013 (2013).

9. Kosaka, T. et al. Catecholaminergic neurons containing GABA-like and/or glutamic acid decarboxylase-like immunoreactivities in various brain regions of the rat. Exp. Brain Res. 66, 191-210, https://doi.org/10.1007/bf00236215 (1987)

10. Baker, H., Kawano, T., Margolis, F. L. \& Joh, T. H. Transneuronal regulation of tyrosine hydroxylase expression in olfactory bulb of mouse and rat. J. Neurosci. 3, 69-78 (1983).

11. Kiyokage, E. et al. Molecular identity of periglomerular and short axon cells. J. Neurosci. 30, 1185-1196, https://doi.org/10.1523/ JNEUROSCI.3497-09.2010 (2010).

12. Kebabian, J. W. Multiple classes of dopamine receptors in mammalian central nervous system: the involvement of dopaminesensitive adenylyl cyclase. Life Sci. 23, 479-483 (1978).

13. Spano, P. F., Govoni, S. \& Trabucchi, M. Studies on the pharmacological properties of dopamine receptors in various areas of the central nervous system. Adv. Biochem. Psychopharmacol. 19, 155-165 (1978).

14. Beaulieu, J. M., Espinoza, S. \& Gainetdinov, R. R. Dopamine receptors - IUPHAR Review 13. Br. J. Pharmacol. 172, 1-23, https://doi. org/10.1111/bph.12906 (2015). 
15. Requardt, R. P., Wilhelm, F., Rillich, J., Winkler, U. \& Hirrlinger, J. The biphasic NAD(P)H fluorescence response of astrocytes to dopamine reflects the metabolic actions of oxidative phosphorylation and glycolysis. J. neurochemistry 115, 483-492, https://doi. org/10.1111/j.1471-4159.2010.06940.x (2010).

16. Requardt, R. P. et al. $\mathrm{Ca}(2)(+)$ signals of astrocytes are modulated by the $\mathrm{NAD}(+) / \mathrm{NADH}$ redox state. J. neurochemistry 120, 1014-1025, https://doi.org/10.1111/j.1471-4159.2012.07645.x (2012).

17. Zanassi, P., Paolillo, M., Montecucco, A., Avvedimento, E. V. \& Schinelli, S. Pharmacological and molecular evidence for dopamine $\mathrm{D}$ (1) receptor expression by striatal astrocytes in culture. J. Neurosci. Res. 58, 544-552 (1999).

18. Liu, C., Kershberg, L., Wang, J., Schneeberger, S. \& Kaeser, P. S. Dopamine Secretion Is Mediated by Sparse Active Zone-like Release Sites. Cell 172, 706-718 e715, https://doi.org/10.1016/j.cell.2018.01.008 (2018).

19. Schnell, C. et al. The multispecific thyroid hormone transporter OATP1C1 mediates cell-specific sulforhodamine 101-labeling of hippocampal astrocytes. Brain Struct. Funct. 220, 193-203, https://doi.org/10.1007/s00429-013-0645-0 (2015).

20. Hulsmann, S., Hagos, L., Heuer, H. \& Schnell, C. Limitations of Sulforhodamine 101 for Brain Imaging. Front. Cell. Neurosci. 11, 44, https://doi.org/10.3389/fncel.2017.00044 (2017).

21. Doengi, M., Deitmer, J. W. \& Lohr, C. New evidence for purinergic signaling in the olfactory bulb: A2A and P2Y1 receptors mediate intracellular calcium release in astrocytes. FASEB J. 22, 2368-2378, https://doi.org/10.1096/f. 07-101782 (2008).

22. Droste, D. et al. Ca(2+)-permeable AMPA receptors in mouse olfactory bulb astrocytes. Sci. Rep. 7, 44817, https://doi.org/10.1038/ srep44817 (2017).

23. Rotermund, N., Schulz, K., Hirnet, D. \& Lohr, C. Purinergic Signaling in the Vertebrate Olfactory System. Front. Cell. Neurosci. 13, 112, https://doi.org/10.3389/fncel.2019.00112 (2019).

24. Doengi, M. et al. GABA uptake-dependent $\mathrm{Ca}(2+)$ signaling in developing olfactory bulb astrocytes. Proc. Natl Acad. Sci. USA 106, 17570-17575, https://doi.org/10.1073/pnas.0809513106 (2009).

25. Mahan, L. C., Burch, R. M., Monsma, F. J. Jr. \& Sibley, D. R. Expression of striatal D1 dopamine receptors coupled to inositol phosphate production and Ca2+ mobilization in Xenopus oocytes. Proc. Natl Acad. Sci. USA 87, 2196-2200, https://doi. org/10.1073/pnas.87.6.2196 (1990).

26. Undie, A. S. \& Friedman, E. Stimulation of a dopamine D1 receptor enhances inositol phosphates formation in rat brain. J. Pharmacol. Exp. Ther. 253, 987-992 (1990).

27. Hasbi, A., O'Dowd, B. F. \& George, S. R. Heteromerization of dopamine D2 receptors with dopamine D1 or D5 receptors generates intracellular calcium signaling by different mechanisms. Curr. Opin. Pharmacol. 10, 93-99, https://doi.org/10.1016/j. coph.2009.09.011 (2010).

28. Hernandez-Lopez, S. et al. D2 dopamine receptors in striatal medium spiny neurons reduce L-type Ca2+ currents and excitability via a novel PLC[beta]1-IP3-calcineurin-signaling cascade. J. Neurosci. 20, 8987-8995 (2000).

29. Jennings, A. et al. Dopamine elevates and lowers astroglial $\mathrm{Ca}(2+)$ through distinct pathways depending on local synaptic circuitry. Glia 65, 447-459, https://doi.org/10.1002/glia.23103 (2017).

30. Otsu, Y. et al. Calcium dynamics in astrocyte processes during neurovascular coupling. Nat. Neurosci. 18, 210-218, https://doi. org/10.1038/nn.3906 (2015).

31. Singaravelu, K., Lohr, C. \& Deitmer, J. W. Regulation of store-operated calcium entry by calcium-independent phospholipase A2 in rat cerebellar astrocytes. J. Neurosci. 26, 9579-9592, https://doi.org/10.1523/JNEUROSCI.2604-06.2006 (2006).

32. Nakahara, K., Okada, M. \& Nakanishi, S. The metabotropic glutamate receptor mGluR5 induces calcium oscillations in cultured astrocytes via protein kinase C phosphorylation. J. neurochemistry 69, 1467-1475, https://doi. org/10.1046/j.1471-4159.1997.69041467.x (1997).

33. Morita, M., Nakane, A., Maekawa, S. \& Kudo, Y. Pharmacological characterization of the involvement of protein kinase C in oscillatory and non-oscillatory calcium increases in astrocytes. J. Pharmacol. Sci. 129, 38-42, https://doi.org/10.1016/j. jphs.2015.08.004 (2015).

34. Rashid, A. J. et al. D1-D2 dopamine receptor heterooligomers with unique pharmacology are coupled to rapid activation of Gq/11 in the striatum. Proc. Natl Acad. Sci. USA 104, 654-659, https://doi.org/10.1073/pnas.0604049104 (2007).

35. Xin, W. et al. Ventral midbrain astrocytes display unique physiological features and sensitivity to dopamine D2 receptor signaling. Neuropsychopharmacology: Off. Publ. Am. Coll. Neuropsychopharmacology 44, 344-355, https://doi.org/10.1038/s41386-018-0151-4 (2019).

36. Perez, M. F., Ford, K. A., Goussakov, I., Stutzmann, G. E. \& Hu, X. T. Repeated cocaine exposure decreases dopamine D(2)-like receptor modulation of $\mathrm{Ca}(2+)$ homeostasis in rat nucleus accumbens neurons. Synap. (N. York, N.Y.) 65, 168-180, https://doi. org/10.1002/syn.20831 (2011).

37. Pignatelli, A. et al. A potential reservoir of immature dopaminergic replacement neurons in the adult mammalian olfactory bulb. Pflug. Arch. 457, 899-915, https://doi.org/10.1007/s00424-008-0535-0 (2009).

38. Pignatelli, A. \& Belluzzi, O. Dopaminergic Neurones in the Main Olfactory Bulb: An Overview from an Electrophysiological Perspective. Front. Neuroanat. 11, 7, https://doi.org/10.3389/fnana.2017.00007 (2017)

39. Nickell, W. T., Norman, A. B., Wyatt, L. M. \& Shipley, M. T. Olfactory bulb DA receptors may be located on terminals of the olfactory nerve. Neuroreport 2, 9-12, https://doi.org/10.1097/00001756-199101000-00002 (1991).

40. Koster, N. L. et al. Olfactory receptor neurons express D2 dopamine receptors. J. Comp. Neurol. 411, 666-673 (1999).

41. Coronas, V., Srivastava, L. K., Liang, J. J., Jourdan, F. \& Moyse, E. Identification and localization of dopamine receptor subtypes in rat olfactory mucosa and bulb: a combined in situ hybridization and ligand binding radioautographic approach. J. Chem. Neuroanat. 12, 243-257 (1997)

42. Thyssen, A. et al. Spatial and developmental heterogeneity of calcium signaling in olfactory ensheathing cells. Glia 61, 327-337, https://doi.org/10.1002/glia.22434 (2013).

43. Yu, Q. et al. Genetic labeling reveals temporal and spatial expression pattern of D2 dopamine receptor in rat forebrain. Brain Struct. Funct. 224, 1035-1049, https://doi.org/10.1007/s00429-018-01824-2 (2019).

44. Mansour, A. et al. Localization of dopamine D2 receptor mRNA and D1 and D2 receptor binding in the rat brain and pituitary: an in situ hybridization-receptor autoradiographic analysis. J. Neurosci. 10, 2587-2600 (1990).

45. Gutierrez-Mecinas, M. et al. Distribution of D2 dopamine receptor in the olfactory glomeruli of the rat olfactory bulb. Eur. J. Neurosci. 22, 1357-1367, https://doi.org/10.1111/j.1460-9568.2005.04328.x (2005).

46. Araujo, A. P. B., Carpi-Santos, R. \& Gomes, F. C. A. The Role of Astrocytes in the Development of the Cerebellum. Cerebellum, https://doi.org/10.1007/s12311-019-01046-0 (2019).

47. Verkhratsky, A., Rodriguez, J. J. \& Parpura, V. Calcium signalling in astroglia. Mol. Cell Endocrinol. 353, 45-56, https://doi. org/10.1016/j.mce.2011.08.039 (2012)

48. Verkhratsky, A. \& Nedergaard, M. Physiology of Astroglia. Physiol. Rev. 98, 239-389, https://doi.org/10.1152/physrev.00042.2016 (2018).

49. Lohr, C., Grosche, A., Reichenbach, A. \& Hirnet, D. Purinergic neuron-glia interactions in sensory systems. Pflug. Arch. 466, 1859-1872, https://doi.org/10.1007/s00424-014-1510-6 (2014).

50. Kozlov, A. S., Angulo, M. C., Audinat, E. \& Charpak, S. Target cell-specific modulation of neuronal activity by astrocytes. Proc. Natl Acad. Sci. USA 103, 10058-10063, https://doi.org/10.1073/pnas.0603741103 (2006).

51. Roux, L. et al. Astroglial Connexin 43 Hemichannels Modulate Olfactory Bulb Slow Oscillations. J. Neurosci. 35, 15339-15352, https://doi.org/10.1523/JNEUROSCI.0861-15.2015 (2015). 
52. Rotermund, N. et al. Adenosine A1 receptor activates background potassium channels and modulates information processing in olfactory bulb mitral cells. J. Physiol. 596, 717-733, https://doi.org/10.1113/JP275503 (2018).

53. Schulz, K. et al. Adenosine A1 Receptor-Mediated Attenuation of Reciprocal Dendro-Dendritic Inhibition in the Mouse Olfactory Bulb. Front. Cell. Neurosci. 11, 435, https://doi.org/10.3389/fncel.2017.00435 (2017).

54. Petzold, G. C., Albeanu, D. F., Sato, T. F. \& Murthy, V. N. Coupling of neural activity to blood flow in olfactory glomeruli is mediated by astrocytic pathways. Neuron 58, 897-910, https://doi.org/10.1016/j.neuron.2008.04.029 (2008).

55. Beiersdorfer, A., Scheller, A., Kirchhoff, F. \& Lohr, C. Panglial gap junctions between astrocytes and olfactory ensheathing cells mediate transmission of $\mathrm{Ca}(2+)$ transients and neurovascular coupling. Glia 67, 1385-1400, https://doi.org/10.1002/glia.23613 (2019).

56. Thyssen, A. et al. Ectopic vesicular neurotransmitter release along sensory axons mediates neurovascular coupling via glial calcium signaling. Proc. Natl Acad. Sci. USA 107, 15258-15263, https://doi.org/10.1073/pnas.1003501107 (2010)

57. Harvey, J. D. \& Heinbockel, T. Neuromodulation of Synaptic Transmission in the Main Olfactory Bulb. Int J Environ Res Public Health 15, https://doi.org/10.3390/ijerph15102194 (2018).

58. Linster, C. \& Cleland, T. A. Neuromodulation of olfactory transformations. Curr. Opin. Neurobiol. 40, 170-177, https://doi. org/10.1016/j.conb.2016.07.006 (2016).

59. McIntyre, J. C., Thiebaud, N., McGann, J. P., Komiyama, T. \& Rothermel, M. Neuromodulation in Chemosensory Pathways. Chem. Senses 42, 375-379, https://doi.org/10.1093/chemse/bjx014 (2017).

60. Fischer, T., Rotermund, N., Lohr, C. \& Hirnet, D. P2Y1 receptor activation by photolysis of caged ATP enhances neuronal network activity in the developing olfactory bulb. Purinergic Signal. 8, 191-198, https://doi.org/10.1007/s11302-011-9286-z (2012).

61. Madisen, L. et al. A robust and high-throughput Cre reporting and characterization system for the whole mouse brain. Nat. Neurosci. 13, 133-140, https://doi.org/10.1038/nn.2467 (2010)

62. Savitt, J. M., Jang, S. S., Mu, W., Dawson, V. L. \& Dawson, T. M. Bcl-x is required for proper development of the mouse substantia nigra. J. Neurosci. 25, 6721-6728, https://doi.org/10.1523/JNEUROSCI.0760-05.2005 (2005).

\section{Acknowledgements}

We thank A.C. Rakete and M. Fink for technical assistance and S. Wiegert for providing TH-Cre mice. This study was supported by grants from the Deutsche Forschungsgemeinschaft (LO 779/10 and SFB 1328 A07 to C.L.).

\section{Author contributions}

T.F. and C.L. conceived the experiments, T.F. and P.S. conducted the experiments, T.F. and P.S. analyzed the results. All authors reviewed the manuscript.

\section{Competing interests}

The authors declare no competing interests.

\section{Additional information \\ Supplementary information is available for this paper at https://doi.org/10.1038/s41598-020-57462-4.}

Correspondence and requests for materials should be addressed to T.F. or C.L.

Reprints and permissions information is available at www.nature.com/reprints.

Publisher's note Springer Nature remains neutral with regard to jurisdictional claims in published maps and institutional affiliations.

Open Access This article is licensed under a Creative Commons Attribution 4.0 International

License, which permits use, sharing, adaptation, distribution and reproduction in any medium or format, as long as you give appropriate credit to the original author(s) and the source, provide a link to the Creative Commons license, and indicate if changes were made. The images or other third party material in this article are included in the article's Creative Commons license, unless indicated otherwise in a credit line to the material. If material is not included in the article's Creative Commons license and your intended use is not permitted by statutory regulation or exceeds the permitted use, you will need to obtain permission directly from the copyright holder. To view a copy of this license, visit http://creativecommons.org/licenses/by/4.0/.

(c) The Author(s) 2020 